Asian J. Med. Biol. Res. 2020, 6 (2), 316-320; doi: 10.3329/ajmbr.v6i2.48078

\author{
Asian Journal of \\ Medical and Biological Research \\ ISSN 2411-4472 (Print) 2412-5571 (Online) \\ www.ebupress.com/journal/ajmbr
}

\title{
Article \\ Cytotoxicity and antimicrobial activity of Dialium ovoideum thwaites, an endemic plant in Sri Lanka
}

\author{
Vajira P. Bulugahapitiya ${ }^{1 *}$, Rathnaweera T. N. ${ }^{1}$, Wijayaratne W. M. D. G. B. ${ }^{2}$ and Manawadu H. C. ${ }^{1}$ \\ ${ }^{1}$ Department of Chemistry, Faculty of Science, University of Ruhuna, Matara 81000, Sri Lanka \\ ${ }^{2}$ Department of Microbiology, Faculty of Medicine, University of Ruhuna, Galle 80000, Sri Lanka
}

"Corresponding author: Vajira P. Bulugahapitiya, Department of Chemistry, faculty of Science, University of Ruhuna, Matara 81000, Sri Lanka. E-mail: vajira@chem.ruh.ac.lk

Received: 01 June 2020/Accepted: 20 June 2020/ Published: 30 June 2020

\begin{abstract}
This study was aimed exploring the cytotoxicity and antimicrobial activity of the leaves $D$. thwaites is an endemic plant to Sri Lanka. The plant is known for its nutritional and medicinal applications where especially the leaf decoctions are being used to wash skin wounds in indigenous medicine. The brine shrimp lethality assays was performed to evaluate normal toxicity and it gave $\mathrm{LC}_{50}$ value greater than $1000 \mu \mathrm{g} / \mathrm{mL}$ showing that the plant extracts are non-toxic to the normal cells. The agar-well diffusion assay was performed to assess the antimicrobial activity, and strains of bacteria; E. coli, Staphylococcus aureus, Pseudomonas aeruginosa and Methicillin Resistant Staphylococcus aureus (MRSA) and fungus; Candida albicans were used as test organisms. The results indicated that all the extracts are active against Staphylococcus aureus (Gram Positive) with maximum inhibition shown for methanolic and aqueous extracts. When it was tested against MRSA both aqueous and methanolic extracts gave similar inhibitions. The minimal inhibitory concentration (MIC) and minimum bactericidal concentration (MBC) were determined as $6.25 \mathrm{mg} / \mathrm{mL}$ and $100 \mathrm{mg} / \mathrm{mL}$ respectively with $S$. aureus whereas no inhibition observed by any of the extract against Gram negative bacteria and Candida albicans. Thus, this study revealed the leaves of $D$. thwaites possesses strong anti-bacterial activity against S. aureus and MRSA. The results confirmed the efficacy of using D. thwaites as the natural antimicrobial agent and suggested to develop the leaves into value added products to be used in topical applications as antiseptic solutions or ointments.
\end{abstract}

Key words: Dialium ovoideum thwaites; antimicrobial; antifungal; cytotoxity; methicillin resistant

\section{Introduction}

The antibiotic resistance (ABR), multidrug resistant (MDR) strain in pathogenic bacteria and the evolution of new strains of disease causing agents, are of great concern to the global health community (Manandha et al., 2019; Giamarellou, 2010). Microbial infections on skin are a frequently occurred health problem as the skin serve as an ecosystem with diverse habitats which the support a wide range of micro-organisms (Grice and Segre, 2011). The pathological situation named "impetigo" is a common bacterial skin infection usually observed on the superficial epidermis and caused by Staphylococcus aureus. This infection accounts for 50\% to $60 \%$ of all bacterial skin infections and topical antibiotic creams such as mupirocin and fusidic acid are prescribed as the treatments (Green et al., 2012). Meanwhile Staphylococcus aureus had also started to develop antibiotic resistance since the introduction of penicillin in 1940 and this situation causes the difficulties to treat such diseases (Boswihi and Udo, 2018). As a solution to penicillin resistance, a semi-synthetic penicillinase resistant penicillin called methicillin had been introduced but shortly Staphylococcus aureus has begun to develop methicillin resistance too (Breyre and Frazee, 2018). This methicillin resistant Staphylococcus aureus (MRSA) has been reported to cause many complications and difficult-to-treat diseases including abscess, purulent cellulitis and even severe skin and soft tissue infections (SSTI) (Kasote et al., 2015) while the number of efficient antibiotics against them are challenging. Therefore, finding potential alternative compounds that can 
be effective in complex situation of microbial infections, through medicinal plants with ethnomedical uses would be the most promising solution as medicinal plants are the sources for potential novel pharmacological active compounds.

The Sri Lankan Ayurvedic system of medicine has been a very long history and been used about 550 to 700 species out of over 3000 vascular plants and a quarter of which is endemic (Yasapalitha and Rupasinghe, 2016). Dialium ovoideum thwaites is such an endemic plant species to Sri Lanka found in the semi-dry zone of the country and is being extensively used in Ayurvedic medicine in the form of leaf decoctions to wash wounds and to treat skin infections (Ayurvedic medicinal plant of Sri Lanka, 2019). It is noteworthy that only a very limited number of scientific studies had been reported of this plant and, therefore in our previous study was carried out to reveal phytochemical, proximate and antioxidant properties of the plant (Bulugahapitiya et al., 2019). Therefore, this an extended study aimed at determining normal toxicity of and assessing antimicrobial activity of the leaves extract of the plant.

\section{Materials and Methods}

\subsection{Plant material}

Leaves were collected from Wellawaya area, Monaragala district, Sri Lanka and were authenticated. Cleaned leaves were blotted and shade dried for 21 days. The dried leavers were ground to fine powder using a blender and were stored in sealed zip-lock bags at $4{ }^{\circ} \mathrm{C}$ until usage.

\subsection{Preparation of extracts}

The methanolic extract was prepared by macerating $160 \mathrm{~g}$ of dried powder in $600 \mathrm{~mL}$ of pure methanol for four days with frequent agitation. The macerated solution was the filtered and concentrated under vacuum. $10 \mathrm{~g}$ of crude was suspended in $150 \mathrm{~mL}$ of distilled water and was sequentially extracted with $50 \mathrm{~mL}$ of each; n-hexane, chloroform and ethyl acetate thrice $(50 \times 3)$ and combined fractions was concentrated under vacuum.

The aqueous extract was prepared by Soxhlet extraction method and was concentrated under high vacuum. All fractions were stored at $4{ }^{\circ} \mathrm{C}$ until test was performed.

\subsection{Determination of normal toxicity using Brine shrimp assay}

Brine shrimp (Artemia salina) lethality assay is commonly used to test the cytotoxic effect of bioactive chemicals such as bioactive natural compounds, toxin, pesticides etc. It is a preliminary toxicity screening used to test the normal toxicity of plant extracts as well (Sarah et al., 2017; Kibiti and Afolayan, 2016). The test is based on the ability to kill a laboratory cultured larvae (nauplii) when exposing them to different concentration of plant extract in sea water within 24 hours time.

\subsubsection{Hatching and preparation of brine shrimp}

Artificial sea water was prepared by dissolving $114.0 \mathrm{~g}$ of $\mathrm{NaCl}$ in $3 \mathrm{~L}(38 \mathrm{~g} / \mathrm{L})$ of water. A spatula full of brine shrimp cysts were added and was incubated for 24 hours at room temperature along with continuous aeration and intensity of $60 \mathrm{~W}$ bulb. The empty cysts and unhatched eggs were separated and the nauplii were pumped out to a new batch of artificial sea water.

\subsubsection{Brine shrimp assay}

A stock solution of $1000 \mathrm{ppm}$ was prepared in artificial sea water with $0.2504 \mathrm{~g}$ of crude methanolic extract and $2 \mathrm{~mL}$ of DMSO. The dilution series was prepared with the concentrations (10 - $1000 \mathrm{ppm})$ while artificial sea water was used as the control. The test solution containing $2.50 \mathrm{~mL}$ of plant extract, $12-15$ nauplii in $10 \mathrm{~mL}$ sea water in test tubes were incubated for 24 hours at room temperature (triplicate). The solutions were quantitatively transferred on to petri dishes and the total and dead counts of nauplii were taken using a magnifying lens. The percentage mortality and the lethal concentration were determined.

$$
\% \text { Mortality }=\frac{\text { No. of dead nauplii }}{\text { Total No. of nauplii }} \times 100 \%
$$

\subsection{Antimicrobial assay}

Antimicrobial assay for the plant extracts were performed using Agar well diffusion method in Mueller Hinton Agar (MHA) plates and minimum inhibitory concentration (MIC) and minimum bactericidal concentration (MBS) were determined according to the method described by Manandhar et al. (2019) with slight modifications. 
2.4.1. Microbial culture used

E.coli (ATCC 25922), Staphylococcus aureus (ATCC 25923), Pseudomonas aeruginosa (ATCC 27853), Candida albicans (ATTC 10231) and a MRSA strain isolated from a clinical specimen were used as test microorganisms and cultures were obtained from Department of Microbiology, Faculty of Medicine, University of Ruhuna, Sri Lanka.

\subsubsection{Antimicrobial assay with plant extracts}

The Muller Hinton's Agar was prepared according to laboratory standards and were autoclaved at $121{ }^{\circ} \mathrm{C}$ for 15 minutes under $15 \mathrm{lb}$ pressure. The sterilized nutrient broths were poured in to sterile petri dishes and were allowed to solidify in a refrigerator. The microbial suspensions were prepared in sterile saline and the concentrations were adjusted to $0.5 \mathrm{McFarland}$ standard. Plant extracts of $200 \mathrm{mg} / \mathrm{mL}$ were prepared in $10 \%$ DMSO. Five wells of $6 \mathrm{~mm}$ were bored in the inoculated media with the help of sterile cork-borer. Each well was loaded with $50 \mu \mathrm{L}$ plant extracts in DMSO, positive control; $5 \mathrm{mg} / \mathrm{mL}$ of vancomycin, ceftriaxone and ceftazidime in DMSO for bacteria and fluconazole for fungi, and $10 \%$ DMSO as negative control respectively. All the inoculated plates were incubated at $35^{\circ} \mathrm{C}$ for $24 \mathrm{~h}$ and plates were observed for inhibition zone. The zone of inhibition (ZOI) were measured in $\mathrm{mm}$ at $18 \mathrm{~h}$ and $24 \mathrm{~h}$.

\subsubsection{Determination of MIC and MBC of plant extract}

The broth microdilution method was used to determine the MIC. Twofold serial dilutions of aqueous and methanolic extracts $(100 \mu \mathrm{L})$ were prepared directly in a well containing Mueller Hinton broth to obtain various concentrations. S. aureus suspension was prepared in $\mathrm{MH}$ broth and the concentration was adjusted to 0.5 McFarland standard. The amount of $100 \mu \mathrm{L}$ of this bacterial suspension was added in to each well and Vancomycin was used as the positive control whereas $10 \%$ DMSO, bacterial suspension and MH broth as negative controls. The plate was covered with a sterile sealer and incubated for $24 \mathrm{~h}$ at $35^{\circ} \mathrm{C}$. The MIC was considered as the lowest concentration of the extract that inhibits the bacterial growth in term of turbidity. In order to determine the minimum bactericidal concentration (MBC), all the serial dilutions of methanolic crude and aqueous fraction resulted from the MIC experiment was sub-cultured on blood agar and minimum concentration of the pant extract which required to kill all the bacterial colonies was measured within fixed time period (24 hours).

\section{Results and Discussion}

\subsection{Preliminary cytotoxicity (Brin shrimp assay)}

Brine shrimp lethality bioassay is a rapid general, bench top bioassay for bioactive compounds and extracts. This assay was first introduced by Michael et al. (1956) to test the toxicity of compounds and then it was further developed by many scientists. Meyer et al. (1982) has successively employed this lethality assay as a bioassay guide for active cytotoxic and antitumor agents. Accordingly, an extract or compound is considered as cytotoxic when the value of $\mathrm{LC}_{50}$ is $\leq 30 \mu \mathrm{g} / \mathrm{mL}$. In this study, the methanolic crude of leaves of $D$. thwaites showed no toxicity towards brine shrimp larvae as lethal concentration $\left(\mathrm{LC}_{50}\right)$ is very large and even greater than $1000 \mathrm{ppm}$ which is taken from the Figure 1 drawn y as percentage mortality $\mathrm{x}$ as $\log$ concentration for the dilution series of D. thwaites.

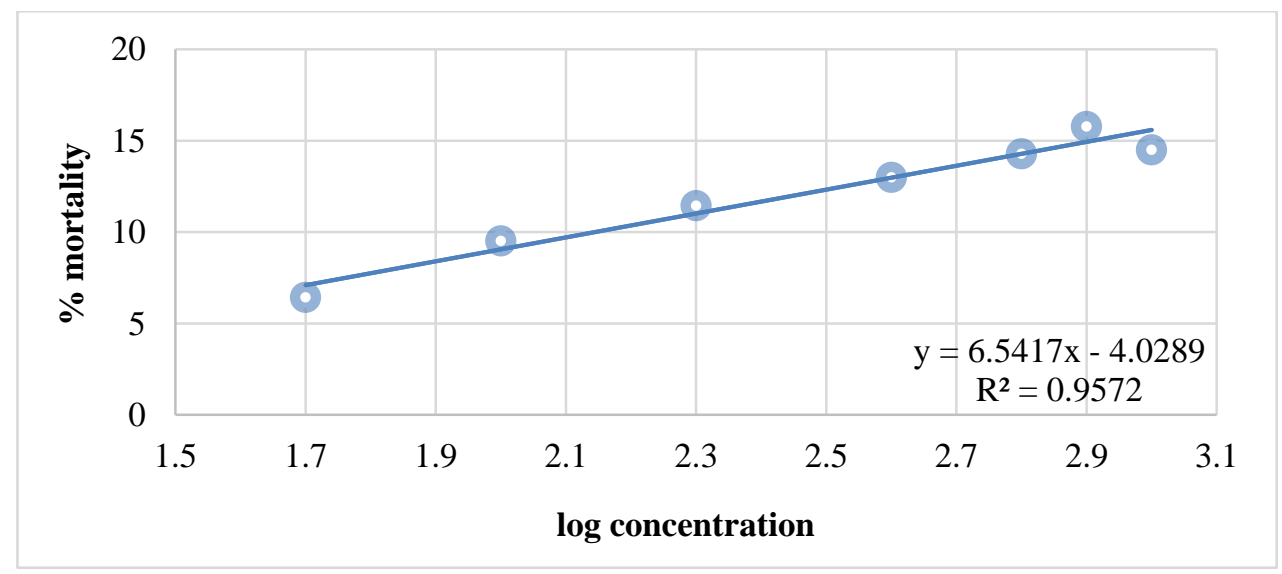

Figure 1. Percentage mortality versus log concentration for the dilution series of $D$. thwaites. 


\subsection{Antimicrobial Activity}

In the preliminary screening, the methanolic crude and the four solvent extracts were tested against gram positive and negative bacteria and the common fungal strain; $C$. albicans. This study showed that all the extracts are inhibitory towards gram positive $S$. aureus while a significant antibacterial activity with respect to vancomycin positive control was shown by the methanolic crude and aqueous extract.

However at the same time it is noteworthy that any of the extracts did not show any inhibition towards the gram negative strains and fungal strain tested. The inhibitory zone diameters were measured after $18 \mathrm{~h}$ and $24 \mathrm{~h}$ of incubation and are summarized in Table 1.

Table 1. Diameters of inhibition zones for solvent extracts against $S$. aureus ATTC reference strain with 5 $\mathrm{mg} / \mathrm{mL}$ vancomycin positive control (mm).

\begin{tabular}{|c|c|c|c|c|c|c|c|c|}
\hline \multicolumn{9}{|c|}{ S. aureus } \\
\hline \multirow[t]{2}{*}{ Extract /Control } & \multicolumn{3}{|c|}{ After $18 \mathrm{~h} / \mathrm{mm}$} & \multirow{2}{*}{$\begin{array}{l}\text { Mean } \\
/ \mathrm{mm}\end{array}$} & \multicolumn{3}{|c|}{ After 24 h /mm } & \multirow{2}{*}{$\begin{array}{l}\text { Mean } \\
/ \mathrm{mm}\end{array}$} \\
\hline & Trial 1 & Trial 2 & Trial 3 & & Trial 1 & Trial 2 & Trial 3 & \\
\hline Methanolic crude & 19 & 18 & 18 & 18.3 & 20 & 19 & 19 & 19.3 \\
\hline Hexane fraction & 12 & 12 & 12 & 12 & 13 & 13 & 13 & 13 \\
\hline $\mathrm{CHCl} 3$ fraction & 14 & 14 & 14 & 14 & 14 & 14 & 14 & 14 \\
\hline Ethyl acetate fraction & 14 & 14 & 14 & 14 & 14 & 14 & 14 & 14 \\
\hline Aqueous fraction & 18 & 18 & 16 & 17.3 & 18 & 18 & 16 & 17.3 \\
\hline Vancomycin & \multicolumn{4}{|c|}{24} & \multicolumn{4}{|c|}{24} \\
\hline $10 \%$ DMSO & \multicolumn{3}{|c|}{0} & & \multicolumn{4}{|c|}{0} \\
\hline
\end{tabular}

Further, inhibitory action of methanolic crude and aqueous crude were tested against clinically isolated MRSA along with vancomycin as the positive control. Surprisingly a significant inhibition was observed at $18 \mathrm{~h}$ and $24 \mathrm{~h}$ as given in the summary of diameter measurements in Table 2.

Table 2. Diameters zones of inhibition for solvent extracts against MRSA clinical isolate (mm).

\begin{tabular}{|c|c|c|c|c|c|c|c|c|}
\hline \multicolumn{9}{|c|}{ MRSA -zone of inhibition (ZOI) in $\mathrm{nm}$} \\
\hline \multirow{2}{*}{ Extract } & \multicolumn{3}{|c|}{ After $18 \mathrm{~h} / \mathrm{mm}$} & \multirow{2}{*}{$\begin{array}{l}\text { Mean } \\
/ \text { /mm }\end{array}$} & \multicolumn{3}{|c|}{ After $24 \mathrm{~h} / \mathrm{mm}$} & \multirow{2}{*}{$\begin{array}{l}\text { Mean } \\
/ \mathrm{mm}\end{array}$} \\
\hline & Trial 11 & Trial 2 & Trial 3 & & Trial 1 & Trial 2 & Trial 3 & \\
\hline Methanolic crude & 16 & 17 & 16 & 16.3 & 16 & 17 & 17 & 16.3 \\
\hline Aqueous fraction & 17 & 17 & 17 & 17 & 17 & 17 & 17 & 17 \\
\hline Vancomycin & \multicolumn{4}{|c|}{25} & \multicolumn{4}{|c|}{25} \\
\hline $10 \%$ DMSO & \multicolumn{4}{|c|}{0} & \multicolumn{4}{|c|}{0} \\
\hline
\end{tabular}

\subsection{Results of MIC and MBC determination}

The effectiveness of the extracts in tested bacterial strains was determined by measuring the minimum inhibitory concentration (MIC) which was done by lowering the concentration of anti-bacterial agent/ plant extract on inhibition of bacterial growth. MIC was performed for only the organisms, S. aureus, which showed a zone of highest inhibition with aqueous and methanolic extracts of leaves in the antimicrobial assay by agar well diffusion method. In this study, MIC value of $6.25 \mathrm{mg} / \mathrm{mL}$ was observed for both methanolic crude and the aqueous extract. While the MIC value of vancomycin, a positive control was recorded to be less than 0.78 $\mathrm{mg} / \mathrm{mL}$. The minimum bactericidal concentration $(\mathrm{MBC})$ is termed as the lowest concentration of antibacterial agent / plant extract required to kill all the bacterial colonies within fixed time period, and study showed that the concentration of $100 \mathrm{mg} / \mathrm{mL}$ of both aqueous and methanolic extracts to be the complete killing of bacterium whereas lesser the concentration more colonies occurred. Therefore, MBC value is reported as $100 \mathrm{mg} / \mathrm{mL}$ for both aqueous and methanolic extracts of $D$. thwaites.

\section{Conclusions}

The study confirmed that the leaf extracts of $D$. thwaites can be used as a potential anti-bacterial candidate against $S$. aureus and especially for MRSA infections which is world-wide health concern. The leaves have no significant antifungal action and no cytotoxicity. The minimum inhibitory concentration (MIC) for both aqueous and methanolic extract of leaves against $S$. aureus is $6.25 \mathrm{mg} / \mathrm{mL}$ whereas minimum bactericidal concentration (MBC) of leaves against $S$. aureus is $100 \mathrm{mg} / \mathrm{mL}$. This study has provided a scientific validation for the use of leaves of $D$. thwaites in antimicrobial purposes in Sri Lankan indigenous medicine. As further advancement, 
development of antibacterial agents from $D$. thwaites against $S$. aureus and MRSA as value added products such as disinfection solution and ointments are promising.

\section{Acknowledgements}

Authors wish to thank Department of Chemistry and Department of Microbiology, University of Ruhuna, Sri Lanka for providing facilities to conduct experiments.

\section{Conflict of interest}

None to declare.

\section{References}

Ayurvedic medicinal plant of Sri Lanka, 2019. http://www.instituteofayurveda.org (accessed January 29, 2019).

Boswihi S and E Udo, 2018. Methicillin-resistant Staphylococcus aureus: an update on the epidemiology, treatment options and infection control. Current Medicine Research and Practice, 8: 18-24.

Breyre A and B Frazee, 2018. Skin and soft tissue infections in the emergency department. Emerg. Med. Clin. N. Am., 36: 723-750.

Bulugahapitiya VP, TN Rathnaweera and HC Manawadu, 2019. Scientific investigation of dialiumovoideum thwaites (gal siyambala) leaves for its phytochemical and anti-oxidant properties. $5^{\text {th }}$ International Symposium on Minor Fruits, Medicinal and Aromatic Plants, September 2019, Institute for Agro Technology and Rural Sciences, Sri Lanka.

Clebak K and M Malone, 2018. Skin Infections. Primary Care: Clinics in Office Practice, 45: 433-454.

Giamarellou H, 2010. Multidrug-resistant Gram-negative bacteria: how to treat and for how long. Int. J. Antimicrob. Agents, 36: S50-54.

Grice E and J Segre, 2011. The skin microbiome. Nat. Rev. Microbiol., 9: 244-253.

Green B, C Johnson, J Egan, M Rosenthal, E Griffith and M Evans, 2012. Methicillin-resistant Staphylococcus aureus: an overview for manual therapists. J. Chiropr. Med., 11: 64-76.

Kasote D, S Katyare, M Hegde and H Bae, 2015. Significance of antioxidant potential of plants and its relevance to therapeutic applications. Int. J. Biol. Sci., 11: 982-991.

Kibiti C and A Afolayan, 2016. Antifungal activity and brine shrimp toxicity assessment of Bulbine abyssinica used in the folk medicine in the Eastern Cape Province, South Africa. Bangladesh J. Pharmacol., 11: 469477.

Meyer BN, NR Ferrigni, JE Putnam, LB Jacobsen, DE Nichols and JL McLaughlin, 1982. Brine shrimp: a convenient general bioassay for active plant constituents. Planta Medica, 45: 31-34.

Michael AS, CG Thampson and M Abramoritz, 1956. Artemia salina as a test organism for bioassay. Science, 123: 464.

QS Sarah, FC Anny and M Misbahuddin, 2017. Brine shrimp lethality assay; visual experiment. Bangladesh J. Pharmacol., 12: 186-189.

Manandhar S, S Luitel and RK Dahal, 2019. In vitro antimicrobial activity of some medicinal plants against human pathogenic bacteria. J. Trop. Med., 2019: 1895340.

Yasapalitha T and R Rupasinghe, 2016. "Sirilaka vana palathuru; 1st ed.; Wasana Book publishers: Dankotuwa, 20-22. 